Revta brasil. Bot., São Paulo, V.24, n.3, p.321-332, set. 2001

\title{
Análise da estrutura de fragmentos florestais no Planalto Paulistano - SP
}

\author{
RICARDO DISLICH $^{1,2}$, LUCIANA CERSÓSIMO e WALDIR MANTOVANI ${ }^{1}$
}

(recebido: 29 de março de 2000; aceito: 20 de junho de 2001)

\begin{abstract}
Analysis of structure of forest fragments in the Paulistano Plateau). The variation in the structure of forest fragments in the Paulistano Plateau, under different viewpoints and spatial scales, is described. A total census of the dominant arboreal component $(\mathrm{GBH} \geq 50 \mathrm{~cm})$ in two areas $(0.5$ ha and $0.2 \mathrm{ha})$ inside a forest fragment, the Cidade Universitária "Armando de Salles Oliveira" (CUASO) Reserve, Butantã, São Paulo, São Paulo State, Southeastern Brazil (approximately $23^{\circ} 34^{\prime} \mathrm{S}, 46^{\circ} 43^{\prime} \mathrm{W}$ ) included 227 individuals belonging to 50 species. A total absolute dominance (Do) of $20.1 \mathrm{~m}^{2} . \mathrm{ha}^{-1}$, a Shannon index $\left(\mathrm{H}^{\prime}\right)$ of 3.04 nats.ind ${ }^{-1}$ and Pielou's evenness $\left(\mathrm{J}^{\prime}\right)$ of $77.79 \%$ were found. Inside each area, regions of concentration of pioneer, secondary and climax species were found. The two areas showed differences in species composition and in the numeric contribution of climax species. Analysing 16 studies in the Paulistano Plateau, a significant Spearman correlation was found between inclusion criterion (GBH) and total absolute density (De), between number of individuals (N) and number of species (S), and between $N$ and percentage of species with one individual $\left(S_{1} / S\right)$. Values of De, $S$ and $S_{1} / S$ were corrected in order to neutralise the effect of $\mathrm{GBH}$ and $\mathrm{N}$, using the residuals of curves adjusted by non-linear regression. After the correction, significant correlations were found among $\mathrm{S}, \mathrm{S}_{1} / \mathrm{S}, \mathrm{H}^{\prime}$ and $\mathrm{J}^{\prime}$, variables related to diversity, but not between De and Do or between any of both and any of the variables related to diversity, pointing to an independence between species diversity and physical structure of the analysed forests. The CUASO forest showed low diversity values relative to the other ones, tentatively explained by its history of succession in isolation.
\end{abstract}

RESUMO - (Análise da estrutura de fragmentos florestais no Planalto Paulistano - SP). Neste trabalho é descrita a variação encontrada na estrutura de fragmentos florestais no Planalto Paulistano, sob diversos aspectos e em diferentes escalas de tamanho. Um censo do componente arbóreo dominante $(\mathrm{PAP} \geq 50 \mathrm{~cm})$ em duas áreas $(0,5$ ha e 0,2 ha) no interior de um fragmento florestal, a Reserva da Cidade Universitária "Armando de Salles Oliveira" (CUASO), Butantã, São Paulo, SP (aproximadamente $23^{\circ} 34^{\prime} \mathrm{S}, 46^{\circ} 43^{\prime} \mathrm{W}$ ) incluiu 227 indivíduos de 50 espécies. Foi encontrada dominância absoluta total (Do) de 20,1 $\mathrm{m}^{2}$.ha ${ }^{-1}$, índice de Shannon $\left(\mathrm{H}^{\prime}\right)$ de 3,04 nats.ind ${ }^{-1}$ e equabilidade de Pielou $\left(\mathrm{J}^{\prime}\right)$ de $77,79 \%$. Em cada área, foram encontradas regiões de concentração de espécies pioneiras, secundárias e climácicas. As duas áreas apresentaram diferenças na composição em espécies e na contribuição numérica de indivíduos de espécies climácicas. Analisando 16 estudos no Planalto Paulistano, encontrou-se correlação de Spearman significativa entre critério de inclusão (PAP) e densidade absoluta total (De), entre número de indivíduos $(\mathrm{N})$ e número de espécies $(\mathrm{S})$, entre $\mathrm{N}$ e porcentagem de espécies com um indivíduo $\left(\mathrm{S}_{1} / \mathrm{S}\right)$.

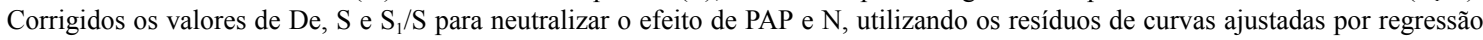
não-linear, foram encontradas correlações significativas entre $\mathrm{S}, \mathrm{S}_{1} / \mathrm{S}, \mathrm{H}^{\prime}$ e $\mathrm{J}^{\prime}$, variáveis ligadas à diversidade, mas não entre De e Do nem entre qualquer destas duas e qualquer das variáveis ligadas à diversidade, indicando independência entre a diversidade específica e a estrutura física das florestas analisadas. A floresta da CUASO apresentou valores de diversidade baixos em relação às outras, tentativamente explicados pelo seu histórico de sucessão em isolamento.

Key words - Ombrophilous dense forest, fragments, structure, diversity

\section{Introdução}

As características da cobertura vegetal original no Planalto Paulistano são pouco conhecidas. Esta região, atualmente coberta em grande parte pela área metropolitana urbana de São Paulo, sofreu influências antrópicas ao longo de quase cinco séculos de ocupação, em decorrência da colonização européia. Mesmo antes de 1500, a região já era um núcleo de povoamento importante para os índios tupiniquins,

1. Universidade de São Paulo, Instituto de Biociências, Departamento de Ecologia Geral, Caixa Postal 11461, 05422-970 São Paulo, SP, Brasil.

2. Autor para correspondência: rdislich@ib.usp.br provavelmente acarretando modificações na vegetação original (Petrone 1995).

Este longo histórico de perturbação antrópica e a conseqüente modificação das condições naturais dificulta sobremaneira a reconstituição da vegetação primitiva na área. Acredita-se, porém, em uma paisagem original predominantemente florestal, às vezes com árvores de Araucaria angustifolia - o pinheiro-do-Paraná - e com a ocorrência de cerrado ou campos confinados a áreas com condições de solo particulares (Ab’Sáber 1963, 1970). Usteri (1911), em um dos primeiros trabalhos sobre a vegetação do município de São Paulo, considerou não haver mais matas primárias na sua área, com exceção do que é hoje o Parque Tenente Siqueira Campos, na Avenida Paulista. Atualmente, pouco resta da vegetação 
nativa no Planalto Paulistano, mesmo alterada, e as poucas áreas cobertas por florestas naturais se apresentam como fragmentos pequenos e dispersos.

A partir da década de 80 foram publicadas informações sobre a flora (Melhem et al. 1981, Baitello \& Aguiar 1982, Pastore et al. 1992, Rossi 1994, Garcia 1995, Gandolfi et al. 1995) e a estrutura do componente arbóreo-arbustivo dos fragmentos florestais atualmente existentes no Planalto Paulistano (De Vuono 1985, Gandolfi 1991, Nastri et al. 1992, Gomes 1992, Baitello et al. 1992, Gorresio-Roizman 1993, Aragaki \& Mantovani 1994, Tabarelli 1994, Knobel 1995, Tomasulo 1995). Os trabalhos realizados indicam a existência de diversidade florística e estrutural elevada entre e dentro dos trechos de floresta estudados. As análises sobre este conjunto de dados, porém, foram realizadas de maneira superficial, desconsiderando as variações nas características físicas do local, a heterogeneidade intrínseca da floresta e o esforço amostral empregado, apenas comparando as floras obtidas (Gomes 1992, Aragaki \& Mantovani 1994). Os dados de levantamentos isolados podem e devem ser sistematizados para possibilitar a construção de hipóteses de trabalho, que possam orientar pesquisas futuras e sintetizar o conhecimento esparso (Torres et al. 1997).

Trabalhos quantitativos sobre florestas usualmente buscam descrever a sua estrutura através de descritores quantitativos - número de indivíduos e/ou área basal por unidade de área amostrada - das diversas espécies. A partir destes dados brutos, são deriváveis outras informações importantes, como a diversidade de espécies e seus componentes - riqueza e equabilidade. Estes resultados estão totalmente ligados ao componente da floresta que é analisado, definido por um critério de inclusão amostral, usualmente um valor de perímetro ou diâmetro mínimo, medido a determinada altura do tronco, a partir do qual as árvores são consideradas como pertencendo à amostra. É intuitivo que estudos na mesma floresta, utilizando critérios de inclusão amostral diferentes, apresentem resultados distintos, e trabalhos que exploram este efeito são inexistentes. A adoção de critérios de inclusão diferentes nos trabalhos quantitativos já realizados no Planalto Paulistano é um de vários fatores complicadores para a comparação e a sistematização dessa floresta.

Este trabalho busca analisar a estrutura, a diversidade de espécies e o estádio sucessional do componente arbóreo dominante de um fragmento florestal e suas variações internas, além de comparar a estrutura de diversos trechos de floresta estudados até o momento no Planalto Paulistano.

\section{Material e métodos}

Local de estudo - A Cidade Universitária "Armando de Salles Oliveira" (CUASO), da Universidade de São Paulo (USP), localiza-se no bairro do Butantã, em São Paulo, SP. Em seu interior, entre $23^{\circ} 33^{\prime} 44^{\prime \prime}$ a $23^{\circ} 34^{\prime} 02^{\prime \prime} \mathrm{S}$ e $46^{\circ} 43^{\prime} 38^{\prime \prime}$ a $46^{\circ} 43^{\prime} 49^{\prime \prime} \mathrm{W}$, localiza-se a reserva estudada neste trabalho, com uma área de $102.100 \mathrm{~m}^{2}$, situada no vale de um riacho que se estende na direção $\mathrm{S}-\mathrm{N}$, em terreno com desnível de $40 \mathrm{~m}$ entre as partes mais altas, a $775 \mathrm{~m}$, e as mais baixas, a $735 \mathrm{~m}$.

A área situa-se na Bacia de São Paulo, formada por depósitos do Terciário e Quaternário (Joly 1950). O solo é essencialmente argiloso, ácido, pobre em nutrientes e com altos teores de alumínio (Gomes 1992).

A temperatura média anual é de $19,2{ }^{\circ} \mathrm{C}$ e precipitação média anual de $1207 \mathrm{~mm}$. As temperaturas médias mensais oscilam entre $14{ }^{\circ} \mathrm{C}$ (junho) e $23{ }^{\circ} \mathrm{C}$ (fevereiro). As precipitações médias mensais vão de $230 \mathrm{~mm}$ em janeiro a $40 \mathrm{~mm}$ em agosto, quando pode ocorrer déficit hídrico no solo (Aragaki \& Mantovani, 1998).

Grande parte da área da Reserva é coberta por mata secundária, formando um mosaico composto por áreas em diversos estádios de degradação e regeneração. A Reserva representa um dos poucos remanescentes da cobertura florestal na cidade de São Paulo, com cerca de 120 espécies arbustivoarbóreas nativas (Rossi 1994). Situada no domínio das florestas ombrófilas densas, a mata apresenta relações florísticas com as florestas ombrófila densa sobre a serra do Mar e a estacional semidecidual (sensu Veloso et al. 1991) no estado de São Paulo.

Obtenção de dados - Foram delimitadas duas áreas dentro da Reserva, formadas por parcelas contíguas de $10 \times 20 \mathrm{~m}$. A área 1 , de $5000 \mathrm{~m}^{2}$, apresenta-se como um retângulo de $100 \mathrm{~m}$ x $50 \mathrm{~m}$. A área 2 , de $2000 \mathrm{~m}^{2}$, localizada em trecho da floresta em estádio sucessional mais recente que o anterior (Rossi 1994), tem formato menos regular, estando ambas dispostas com seus lados maiores aproximadamente paralelos ao riacho.

Em cada uma das áreas, foi feito um censo das árvores vivas de caule com perímetro a $1,30 \mathrm{~m}$ de altura do solo (perímetro à altura do peito - $\mathrm{PAP}) \geq 50 \mathrm{~cm}$. Com este critério de inclusão, buscou-se analisar apenas as árvores do dossel e emergentes, que formam o componente dominante da mata.

Cada árvore amostrada recebeu uma plaqueta de alumínio com um número de identificação, tendo medida a sua altura máxima e o PAP. Nos casos em que havia mais de um caule vivo a $1,30 \mathrm{~m}$ de altura, eram medidos todos os caules. O levantamento na área 1 foi completado em junho de 1992 e o da área 2 em março de 1994.

O material botânico coletado para identificação foi prensado e seco em estufa. A identificação foi feita com auxílio da chave publicada por Rossi (1994) e através da comparação com material depositado no Herbário do Instituto de Botânica de São Paulo (SP), adotando-se o sistema de Cronquist (1981). Material identificado como espécie não observada por Rossi (1994) foi incluído no Herbário do 
Departamento de Botânica do Instituto de Biociências da Universidade de São Paulo (SPF).

Informações sobre o estádio sucessional de cada uma das espécies, considerando-se sua exigência de luz e seu ciclo de vida, foram obtidas na literatura, que indica a classificação sucessional de espécies de plantas bastante polêmica, por não terem sido efetuados estudos populacionais detalhados (Gandolfi et al. 1995, Tabarelli \& Mantovani 1997). Foram consideradas espécies climácicas aquelas citadas como tal ou como "secundárias tardias"; como secundárias, as citadas como "secundárias iniciais" ou "secundárias"; e como pioneiras, as citadas como tal.

Análise de dados - Para cada espécie, foram calculados os seguintes parâmetros quantitativos (Mueller-Dombois \& Ellenberg 1974), em sua forma absoluta e relativa: densidade, dominância e freqüência, esta última considerando parcelas de $10 \times 20 \mathrm{~m}$, além do valor de importância (VI).

A curva espécies $x$ área (Mueller-Dombois \& Ellenberg 1974) foi elaborada através da contagem do número de espécies acumulado em 15 seqüências aleatórias de 70 parcelas de $10 \times 10 \mathrm{~m}$. Posteriormente, calcularam-se a média amostral e o intervalo de confiança $(95 \%)$ para a média populacional para cada número de parcelas. Procedimento correspondente foi utilizado para a construção de uma curva espécies $\mathrm{x}$ número de indivíduos.

A diversidade de espécies foi medida através do índice de Shannon e Wiener (H') (Magurran 1988), calculado com base no logaritmo natural, e a equabilidade através do índice de Pielou (J') (Pielou 1975).

A vegetação foi classificada de acordo com seu estádio sucessional, adotando-se um dos critérios propostos por Budowski (1970): a proporção relativa entre o número de indivíduos de espécies iniciais (pioneiras e secundárias) e o de tardias (climácicas) que compõem o dossel da mata, considerando-se mais de $50 \%$ dos indivíduos de um estádio como determinante deste.

Os parâmetros quantitativos foram comparados com os de 15 outros estudos realizados sobre a estrutura de seis fragmentos florestais no Planalto Paulistano. Nesta comparação, foram utilizadas as seguintes variáveis, divididas em dois grupos:

(1) variáveis metodológicas, derivadas direta ou indiretamente de decisões do(s) autor(es) na tomada de dados: critério de inclusão (PAP) e número de indivíduos amostrados (N); no caso de levantamentos usando o método de parcelas, $\mathrm{N}$ não é determinado a priori pelo autor, como acontece com o PAP, mas o autor decide indiretamente qual será o $\mathrm{N}$ através do número e do tamanho das parcelas utilizadas. Se o $\mathrm{N}$ obtido for considerado pequeno, o autor pode aumentar o número de parcelas amostradas durante o trabalho de campo.

(2) variáveis estruturais, referentes a resultados obtidos no estudo: número de espécies obtidas (S), proporção de espécies representadas por apenas um indivíduo $\left(\mathrm{S}_{1} / \mathrm{S}\right)$, diversidade $\left(\mathrm{H}^{\prime}\right)$, equabilidade (J'), densidade absoluta total (De) e dominância absoluta (área basal) total (AB). Estas variáveis são apresentadas comumente em trabalhos que descrevem a estrutura de florestas ou podem ser facilmente calculados a partir de dados que são apresentados.

Foi calculado o coeficiente de correlação nãoparamétrico de Spearman $\left(\mathrm{r}_{\mathrm{s}}\right.$ ) (Zar 1999) e o respectivo nível de significância (p) entre as variáveis metodológicas e cada uma das variáveis estruturais. Para os pares de variáveis em que se detectou correlação significativa $(\mathrm{p}<0,01)$ buscou-se o melhor ajuste de curva entre cinco modelos diferentes (linear, logarítmico, polinomial, de potência e exponencial), utilizando-se o programa Microsoft Excel 95 e considerando a variável metodológica como independente. Foi considerado como melhor ajuste aquele de maior coeficiente de determinação $\mathrm{r}^{2}$ (Zar 1999). Os resíduos das variáveis dependentes (valor observado menos valor previsto pela curva ajustada) foram então utilizados como "valores corrigidos" destas variáveis para a análise posterior, em que foi calculado o índice de Spearman e o respectivo p para cada par de variáveis estruturais.

\section{Resultados}

Área total - Foram amostrados, no total, 227 indivíduos, pertencentes a 50 espécies de 39 gêneros e 25 famílias (tabela 1). As famílias com maiores números de espécies foram Lauraceae (sete espécies), Fabaceae (seis), Myrtaceae (quatro) e Euphorbiaceae (três). Os gêneros com maiores riquezas foram Machaerium e Ocotea, com três espécies cada um.

Das espécies descritas por Rossi (1994) em seu levantamento florístico de fanerógamas arbóreas e arbustivas da Reserva, cerca de 80 podem alcançar o tamanho utilizado como critério amostral neste trabalho. Pouco mais da metade destas (43) foi encontrado, além de outras sete espécies não tratadas por Rossi (1994) (tabela 1), aumentando em 8,75\% o número de espécies que chegam a este tamanho na Reserva. Uma das espécies não anteriormente citadas foi uma Pteridophyta arborescente (Cyathea delgadii Sternb.) (samambaiuçu). Archontophoenix cunninghamiana $\mathrm{H}$. Wendl. \& Drude é uma palmeira nativa da Austrália, cultivada como ornamental nos jardins da malha urbana que cerca o local de estudos, que invadiu e se estabeleceu na Reserva.

A figura 1 mostra o crescimento do número de espécies com o aumento da área (curva espécies $\mathrm{x}$ área) e do número de indivíduos amostrados (curva espécies $\mathrm{x}$ indivíduos). As duas curvas indicam incremento de espécies com o esforço amostral efetuado.

A densidade total obtida foi de 324 indivíduos.ha ${ }^{-1} \mathrm{e}$ a área basal total, 20,1 $\mathrm{m}^{2}$.ha- (tabela 1). O índice de Shannon e Wiener ( $\left.H^{\prime}\right)$ calculado foi de 3,04 nats.ind ${ }^{-1}$, e o de equabilidade de Pielou $\left(\mathrm{J}^{\prime}\right)$, de $77,79 \%$. Cinco espécies (10\% do total) abrangeram mais da metade dos indivíduos amostrados, e apenas quatro (8\%) foram responsáveis por mais de $50 \%$ da área basal total. Vinte e uma espécies (42\%) foram representadas por apenas um indivíduo. 
Tabela 1. Famílias, espécies amostradas e estádio sucessional a que pertencem na Reserva da Cidade Universitária "Armando de Salles Oliveira", São Paulo, SP.

\begin{tabular}{|c|c|c|}
\hline Familia & Espécie & Estádio sucessional \\
\hline Anacardiaceae & Tapirira guianensis Aubl. & climácica \\
\hline \multirow[t]{2}{*}{ Annonaceae } & Rollinia sericea R.E. Fr. & climácica \\
\hline & Rollinia sylvatica (A. St.-Hil.) Mart.* & climácica \\
\hline \multirow[t]{2}{*}{ Arecaceae } & Archontophoenix cunninghamiana H.Wendl. \& Drude & secundária \\
\hline & Syagrus romanzoffiana (Cham.) Glassm. & secundária \\
\hline Bombacaceae & Chorisia speciosa A. St.-Hil. & secundária \\
\hline \multirow[t]{2}{*}{ Boraginaceae } & Cordia ecalyculata Vell. & climácica \\
\hline & Cordia sellowiana Cham. & secundária \\
\hline Caesalpiniaceae & Copaifera langsdorffii Desf. & climácica \\
\hline \multirow[t]{2}{*}{ Cecropiaceae } & Cecropia glazioui Snethl. & pioneira \\
\hline & Cecropia hololeuca Miq.* & pioneira \\
\hline \multirow[t]{2}{*}{ Celastraceae } & Maytenus evonymoides Reiss. & climácica \\
\hline & Maytenus robusta Reiss. & secundária \\
\hline Cyatheaceae & Cyathea delgadii Sternb.* & climácica \\
\hline Elaeocarpaceae & Sloanea monosperma Vell. & climácica \\
\hline \multirow[t]{3}{*}{ Euphorbiaceae } & Alchornea triplinervia (Spreng.) Müll. Arg. & secundária \\
\hline & Alchornea sidifolia Müll. Arg. & pioneira \\
\hline & Croton floribundus Spreng. & pioneira \\
\hline \multirow[t]{6}{*}{ Fabaceae } & Andira anthelmia (Vell.) Macbr. & secundária \\
\hline & Machaerium nyctitans (Vell.) Benth. & secundária \\
\hline & Machaerium stipitatum (DC.) Vog. & secundária \\
\hline & Machaerium villosum Vog. & climácica \\
\hline & Pterocarpus rohrii Vahl.* & climácica \\
\hline & Zollernia ilicifolia Vog. & climácica \\
\hline Flacourtiaceae & Casearia sylvestris $\mathrm{Sw}$. & secundária \\
\hline \multirow[t]{7}{*}{ Lauraceae } & Cinnamomum triplinerve (Ruiz \& Pav.) Kosterm. & climácica \\
\hline & Endlicheria paniculata (Spreng.) Macbr. & climácica \\
\hline & Nectandra grandiflora Nees & climácica \\
\hline & Nectandra puberula Nees & climácica \\
\hline & Ocotea laxa (Nees) Mez & climácica \\
\hline & Ocotea odorifera (Vell.) Rohwer* & climácica \\
\hline & Ocotea puberula (Rich.) Nees & climácica \\
\hline Melastomataceae & Tibouchina granulosa Cogn. & pioneira \\
\hline \multirow[t]{2}{*}{ Meliaceae } & Cabralea canjerana (Vell.) Mart. & secundária \\
\hline & Cedrela fissilis Vell. & climácica \\
\hline \multirow[t]{2}{*}{ Mimosaceae } & Inga sessilis (Vell.) Mart. & climácica \\
\hline & Piptadenia gonoacantha (Mart.) Macbr. & pioneira \\
\hline \multirow[t]{2}{*}{ Moraceae } & Ficus insipida Willd. & climácica \\
\hline & Sorocea bonplandii (Baill.) Burg., Lanj. \& Boer & climácica \\
\hline \multirow[t]{4}{*}{ Myrtaceae } & Campomanesia guaviroba (DC.) Kiaerskov* & secundária \\
\hline & Eugenia cerasiflora Miq. & climácica \\
\hline & Eugenia sphenophylla O. Berg & climácica \\
\hline & Myrcia multiflora (Lam.) DC.* & climácica \\
\hline Oleaceae & Linociera arborea Eichl. & climácica \\
\hline Rosaceae & Prunus sellowii Koehne & secundária \\
\hline Rubiaceae & Guettarda viburnoides Cham. \& Schlecht. & climácica \\
\hline Sapindaceae & Cupania oblongifolia Mart. & climácica \\
\hline Solanaceae & Solanum erianthum D. Don & pioneira \\
\hline \multirow[t]{2}{*}{ Verbenaceae } & Citharexylum myrianthum Cham. & pioneira \\
\hline & Vitex polygama Cham. & climácica \\
\hline
\end{tabular}

* Espécies não citadas por Rossi (1994). 

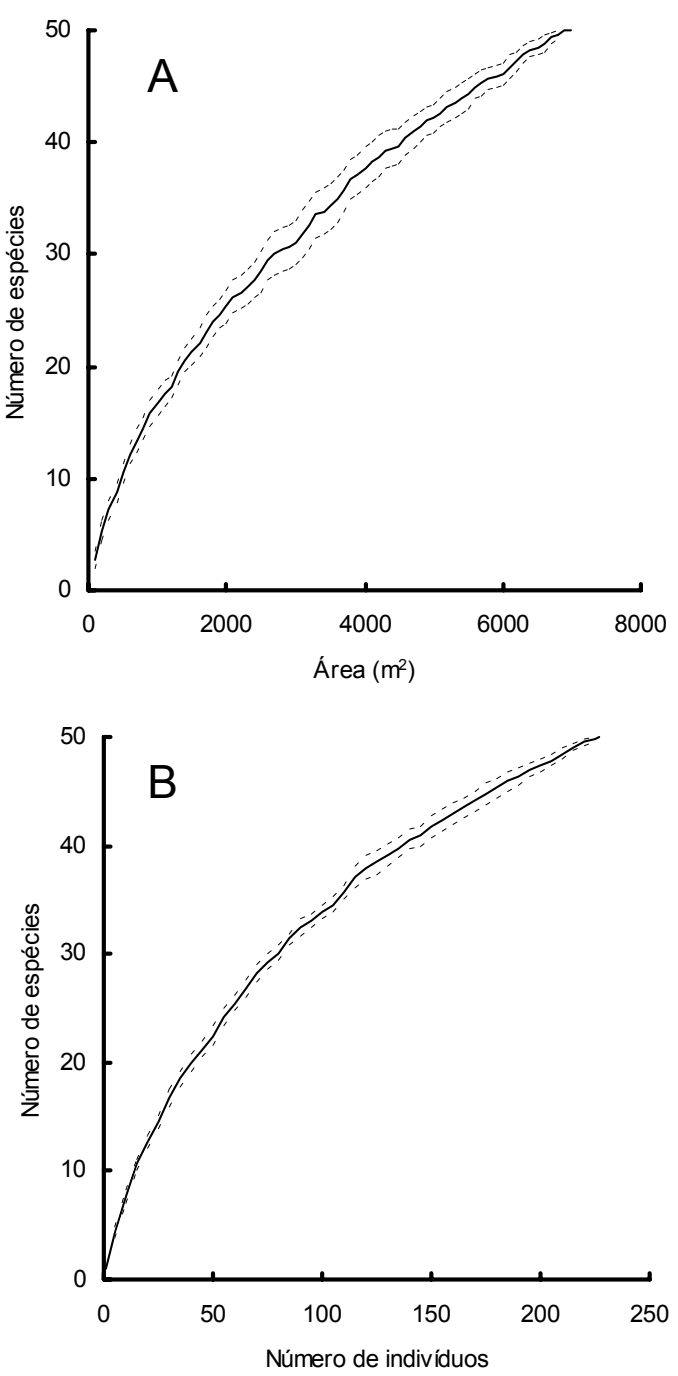

Figura 1. Curva espécies $x$ área (A) e espécies $x$ indivíduos (B) para a área total amostrada na Reserva da Cidade Universitária "Armando de Salles Oliveira", São Paulo, SP. Os pontos representam a média amostral obtida $(\mathrm{n}=15)$ e os tracejados, os intervalos de confiança (95\%) para a média.

A média de altura das árvores foi de $14,5 \mathrm{~m}$, com desvio-padrão de $2,9 \mathrm{~m}$, variando entre $5,5 \mathrm{~m}$ (Cyathea delgadii) e 22,5 m (um exemplar de Cedrela fissilis com $200 \mathrm{~cm}$ de perímetro). A árvore com maior perímetro foi um exemplar de Machaerium villosum, com $204 \mathrm{~cm}$, embora a árvore com maior área basal tenha sido um exemplar de Machaerium nyctitans, com quatro troncos $(175 \mathrm{~cm}, 150 \mathrm{~cm}, 62,5 \mathrm{~cm}$ e $39,5 \mathrm{~cm}$ de perímetro à altura do peito), totalizando área basal de $0,47 \mathrm{~m}^{2}$.
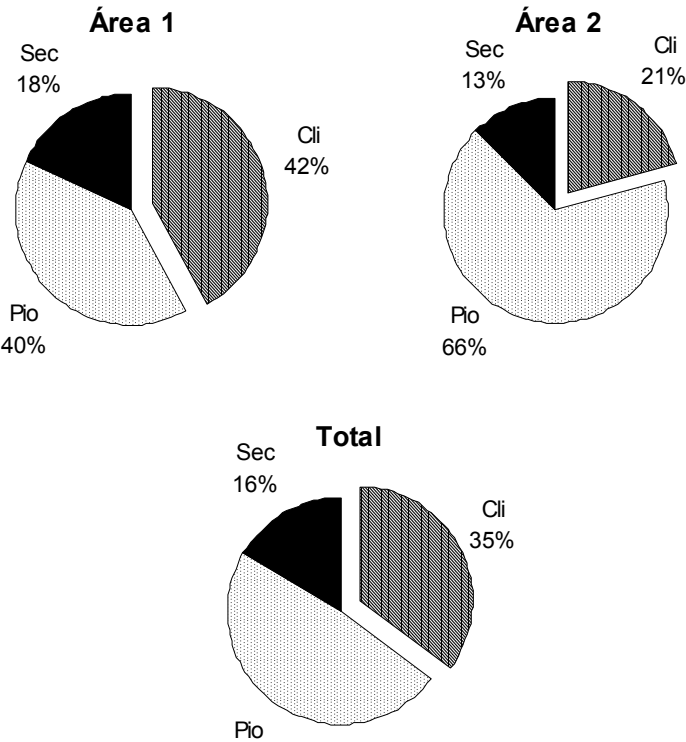

$49 \%$

Figura 2. Porcentagem de indivíduos pertencentes a cada categoria sucessional, na área 1, na área 2 e no total amostrado, na Reserva da Cidade Universitária "Armando de Salles Oliveira", São Paulo, SP.

Alchornea sidifolia e Croton floribundus, consideradas pioneiras (tabela 1), foram as espécies com os maiores valores de todos os parâmetros quantitativos (tabela 2). Cordia ecalyculata apresentou-se com os terceiros valores em densidade e freqüência. Em termos de dominância, porém, Machaerium nyctitans, Piptadenia gonoacantha e Cedrela fissilis, nesta ordem, apresentaram valores superiores ao de C. ecalyculata (tabela 2), porque os indivíduos desta última espécie tiveram, em média, áreas basais menores que os daquelas.

Oito espécies foram consideradas pioneiras, 13 secundárias e o restante (58\%), climácicas (tabela 1). A análise de estádio sucessional indicou $49 \%$ dos indivíduos como pertencentes a espécies pioneiras, $16 \%$ a espécies secundárias e $35 \%$ a espécies climácicas (figura 2).

Comparação entre área 1 e área 2 - As duas áreas amostradas apresentaram diferenças importantes, principalmente com relação à composição da comunidade (tabela 3). Cordia ecalyculata, com a terceira população em densidade na área 1 , não ocorreu na área 2. Já Piptadenia gonoacantha não ocorreu na área 1 , mas foi a espécie com a terceira maior densidade na área 2. Das 29 espécies 
Tabela 2. Parâmetros quantitativos das espécies amostradas na Reserva da Cidade Universitária "Armando de Salles Oliveira", São Paulo, SP. N: número de indivíduos; DA: densidade absoluta (ind.ha-1); DR: densidade relativa (\%); DoA: dominância absoluta $\left(\mathrm{m}^{2} \cdot \mathrm{ha}^{-1}\right)$; DoR: dominância relativa (\%); FA: freqüência absoluta (\%); FR: freqüência relativa (\%);VI: valor de importância.

\begin{tabular}{|c|c|c|c|c|c|c|c|c|}
\hline Espécie & $\mathrm{N}$ & $\mathrm{DA}$ & $\mathrm{DR}$ & DoA & DoR & FA & FR & $\overline{\mathrm{VI}}$ \\
\hline Alchornea sidifolia & 58 & 82,9 & 25,6 & 5,80 & 28,8 & 74,3 & 16,4 & 70,7 \\
\hline Croton floribundus & 32 & 45,7 & 14,1 & 2,34 & 11,6 & 45,7 & 10,1 & 35,8 \\
\hline Cordia ecalyculata & 18 & 25,7 & 7,9 & 0,84 & 4,2 & 34,3 & 7,5 & 19,7 \\
\hline Piptadenia gonoacantha & 8 & 11,4 & 3,5 & 1,02 & 5,1 & 11,4 & 2,5 & 11,1 \\
\hline Maytenus evonymoides & 8 & 11,4 & 3,5 & 0,39 & 1,9 & 22,9 & 5,0 & 10,5 \\
\hline Machaerium nyctitans & 5 & 7,1 & 2,2 & 1,09 & 5,4 & 11,4 & 2,5 & 10,1 \\
\hline Cedrela fissilis & 5 & 7,1 & 2,2 & 0,90 & 4,5 & 11,4 & 2,5 & 9,2 \\
\hline Cinnamomum triplinerve & 6 & 8,6 & 2,6 & 0,50 & 2,5 & 17,1 & 3,8 & 8,9 \\
\hline Casearia sylvestris & 7 & 10,0 & 3,1 & 0,41 & 2,0 & 17,1 & 3,8 & 8,9 \\
\hline Cecropia glazioui & 6 & 8,6 & 2,6 & 0,48 & 2,4 & 17,1 & 3,8 & 8,8 \\
\hline Machaerium villosum & 3 & 4,3 & 1,3 & 0,72 & 3,6 & 8,6 & 1,9 & 6,8 \\
\hline Archonthophoenix cunninghamiana & 5 & 7,1 & 2,2 & 0,35 & 1,8 & 11,4 & 2,5 & 6,5 \\
\hline Andira anthelmia & 5 & 7,1 & 2,2 & 0,32 & 1,6 & 11,4 & 2,5 & 6,3 \\
\hline Eugenia cerasiflora & 5 & 7,1 & 2,2 & 0,20 & 1,0 & 11,4 & 2,5 & 5,7 \\
\hline Rollinia sericea & 3 & 4,3 & 1,3 & 0,27 & 1,4 & 8,6 & 1,9 & 4,6 \\
\hline Nectandra grandiflora & 3 & 4,3 & 1,3 & 0,27 & 1,3 & 8,6 & 1,9 & 4,6 \\
\hline Ficus insipida & 1 & 1,4 & 0,4 & 0,69 & 3,4 & 2,9 & 0,6 & 4,5 \\
\hline Prunus sellowii & 3 & 4,3 & 1,3 & 0,22 & 1,1 & 8,6 & 1,9 & 4,3 \\
\hline Rollinia sylvatica & 3 & 4,3 & 1,3 & 0,32 & 1,6 & 5,7 & 1,3 & 4,2 \\
\hline Alchornea triplinervia & 2 & 2,9 & 0,9 & 0,30 & 1,5 & 5,7 & 1,3 & 3,6 \\
\hline Sorocea bonplandii & 3 & 4,3 & 1,3 & 0,15 & 0,7 & 5,7 & 1,3 & 3,3 \\
\hline Machaerium stipitatum & 2 & 2,9 & 0,9 & 0,19 & 0,9 & 5,7 & 1,3 & 3,1 \\
\hline Guettarda viburnoides & 2 & 2,9 & 0,9 & 0,15 & 0,7 & 5,7 & 1,3 & 2,9 \\
\hline Cordia sellowiana & 2 & 2,9 & 0,9 & 0,14 & 0,7 & 5,7 & 1,3 & 2,8 \\
\hline Inga sessilis & 2 & 2,9 & 0,9 & 0,13 & 0,6 & 5,7 & 1,3 & 2,8 \\
\hline Citharexylum myrianthum & 2 & 2,9 & 0,9 & 0,12 & 0,6 & 5,7 & 1,3 & 2,7 \\
\hline Solanum erianthum & 2 & 2,9 & 0,9 & 0,10 & 0,5 & 5,7 & 1,3 & 2,6 \\
\hline Cupania oblongifolia & 2 & 2,9 & 0,9 & 0,10 & 0,5 & 5,7 & 1,3 & 2,6 \\
\hline Pterocarpus rohrii & 1 & 1,4 & 0,4 & 0,30 & 1,5 & 2,9 & 0,6 & 2,6 \\
\hline Nectandra puberula & 2 & 2,9 & 0,9 & 0,12 & 0,6 & 2,9 & 0,6 & 2,1 \\
\hline Cabralea canjerana & 2 & 2,9 & 0,9 & 0,10 & 0,5 & 2,9 & 0,6 & 2,0 \\
\hline Chorisia speciosa & 1 & 1,4 & 0,4 & 0,12 & 0,6 & 2,9 & 0,6 & 1,7 \\
\hline Ocotea puberula & 1 & 1,4 & 0,4 & 0,12 & 0,6 & 2,9 & 0,6 & 1,7 \\
\hline Zollernia ilicifolia & 1 & 1,4 & 0,4 & 0,10 & 0,5 & 2,9 & 0,6 & 1,6 \\
\hline Cecropia hololeuca & 1 & 1,4 & 0,4 & 0,08 & 0,4 & 2,9 & 0,6 & 1,5 \\
\hline Sloanea monosperma & 1 & 1,4 & 0,4 & 0,07 & 0,3 & 2,9 & 0,6 & 1,4 \\
\hline Vitex polygama & 1 & 1,4 & 0,4 & 0,06 & 0,3 & 2,9 & 0,6 & 1,4 \\
\hline Tibouchina granulosa & 1 & 1,4 & 0,4 & 0,06 & 0,3 & 2,9 & 0,6 & 1,4 \\
\hline Syagrus romanzoffiana & 1 & 1,4 & 0,4 & 0,06 & 0,3 & 2,9 & 0,6 & 1,4 \\
\hline Myrcia multiflora & 1 & 1,4 & 0,4 & 0,05 & 0,2 & 2,9 & 0,6 & 1,3 \\
\hline Tapirira guianensis & 1 & 1,4 & 0,4 & 0,05 & 0,2 & 2,9 & 0,6 & 1,3 \\
\hline Endlicheria paniculata & 1 & 1,4 & 0,4 & 0,05 & 0,2 & 2,9 & 0,6 & 1,3 \\
\hline Ocotea laxa & 1 & 1,4 & 0,4 & 0,05 & 0,2 & 2,9 & 0,6 & 1,3 \\
\hline Copaifera langsdorffii & 1 & 1,4 & 0,4 & 0,04 & 0,2 & 2,9 & 0,6 & 1,3 \\
\hline Eugenia sphenophylla & 1 & 1,4 & 0,4 & 0,04 & 0,2 & 2,9 & 0,6 & 1,3 \\
\hline Maytenus robusta & 1 & 1,4 & 0,4 & 0,04 & 0,2 & 2,9 & 0,6 & 1,3 \\
\hline Linociera arborea & 1 & 1,4 & 0,4 & 0,04 & 0,2 & 2,9 & 0,6 & 1,2 \\
\hline Ocotea odorifera & 1 & 1,4 & 0,4 & 0,03 & 0,2 & 2,9 & 0,6 & 1,2 \\
\hline Campomanesia guaviroba & 1 & 1,4 & 0,4 & 0,03 & 0,1 & 2,9 & 0,6 & 1,2 \\
\hline Cyathea delgadii & 1 & 1,4 & 0,4 & 0,03 & 0,1 & 2,9 & 0,6 & 1,2 \\
\hline Total & 227 & 324,3 & 100,0 & 20,13 & 100,0 & 454,3 & 100,0 & 300 \\
\hline
\end{tabular}


Revta brasil. Bot., São Paulo, V.24, n.3, p.321-332, set. 2001

Tabela 3. Número de indivíduos amostrados $(\mathrm{N})$, densidade absoluta (DA, ind.ha ${ }^{-1}$ ) e densidade relativa (DR, \%) da cada espécie em cada área amostrada, Reserva da Cidade Universitária "Armando de Salles Oliveira", São Paulo, SP.

\begin{tabular}{|c|c|c|c|c|c|c|}
\hline \multirow[t]{2}{*}{ Espécie } & \multicolumn{2}{|c|}{$\mathrm{N}$} & \multicolumn{2}{|c|}{ DA } & \multicolumn{2}{|c|}{$\mathrm{DR}$} \\
\hline & Area 1 & Area 2 & Area 1 & Area 2 & Area 1 & Area 2 \\
\hline Alchornea sidifolia & 32 & 26 & 64 & 130 & 20,6 & 36,1 \\
\hline Croton floribundus & 22 & 10 & 44 & 50 & 14,2 & 13,9 \\
\hline Cordia ecalyculata & 18 & 0 & 36 & 0 & 11,6 & 0,0 \\
\hline Piptadenia gonoacantha & 0 & 8 & 0 & 40 & 0,0 & 11,1 \\
\hline Maytenus evonymoides & 6 & 2 & 12 & 10 & 3,9 & 2,8 \\
\hline Casearia sylvestris & 5 & 2 & 10 & 10 & 3,2 & 2,8 \\
\hline Cecropia glazioui & 4 & 2 & 8 & 10 & 2,6 & 2,8 \\
\hline Cinnamomum triplinerve & 2 & 4 & 4 & 20 & 1,3 & 5,6 \\
\hline Andira anthelmia & 2 & 3 & 4 & 15 & 1,3 & 4,2 \\
\hline Archonthophoenix cunninghamiana & 3 & 2 & 6 & 10 & 1,9 & 2,8 \\
\hline Cedrela fissilis & 4 & 1 & 8 & 5 & 2,6 & 1,4 \\
\hline Eugenia cerasiflora & 5 & 0 & 10 & 0 & 3,2 & 0,0 \\
\hline Machaerium nyctitans & 3 & 2 & 6 & 10 & 1,9 & 2,8 \\
\hline Machaerium villosum & 3 & 0 & 6 & 0 & 1,9 & 0,0 \\
\hline Nectandra grandiflora & 2 & 1 & 4 & 5 & 1,3 & 1,4 \\
\hline Prunus sellowii & 3 & 0 & 6 & 0 & 1,9 & 0,0 \\
\hline Rollinia sericea & 2 & 1 & 4 & 5 & 1,3 & 1,4 \\
\hline Rollinia sylvatica & 3 & 0 & 6 & 0 & 1,9 & 0,0 \\
\hline Sorocea bonplandii & 3 & 0 & 6 & 0 & 1,9 & 0,0 \\
\hline Alchornea triplinervia & 2 & 0 & 4 & 0 & 1,3 & 0,0 \\
\hline Cabralea canjerana & 2 & 0 & 4 & 0 & 1,3 & 0,0 \\
\hline Citharexylum myrianthum & 0 & 2 & 0 & 10 & 0,0 & 2,8 \\
\hline Guettarda viburnoides & 1 & 1 & 2 & 5 & 0,6 & 1,4 \\
\hline Inga sessilis & 1 & 1 & 2 & 5 & 0,6 & 1,4 \\
\hline Cordia sellowiana & 2 & 0 & 4 & 0 & 1,3 & 0,0 \\
\hline Cupania oblongifolia & 2 & 0 & 4 & 0 & 1,3 & 0,0 \\
\hline Machaerium stipitatum & 2 & 0 & 4 & 0 & 1,3 & 0,0 \\
\hline Nectandra puberula & 2 & 0 & 4 & 0 & 1,3 & 0,0 \\
\hline Solanum erianthum & 2 & 0 & 4 & 0 & 1,3 & 0,0 \\
\hline Campomanesia guaviroba & 1 & 0 & 2 & 0 & 0,6 & 0,0 \\
\hline Cecropia hololeuca & 1 & 0 & 2 & 0 & 0,6 & 0,0 \\
\hline Chorisia speciosa & 1 & 0 & 2 & 0 & 0,6 & 0,0 \\
\hline Endlicheria paniculata & 1 & 0 & 2 & 0 & 0,6 & 0,0 \\
\hline Ficus insipida & 1 & 0 & 2 & 0 & 0,6 & 0,0 \\
\hline Linociera arborea & 1 & 0 & 2 & 0 & 0,6 & 0,0 \\
\hline Maytenus robusta & 1 & 0 & 2 & 0 & 0,6 & 0,0 \\
\hline Myrcia multiflora & 1 & 0 & 2 & 0 & 0,6 & 0,0 \\
\hline Ocotea laxa & 1 & 0 & 2 & 0 & 0,6 & 0,0 \\
\hline Ocotea odorifera & 1 & 0 & 2 & 0 & 0,6 & 0,0 \\
\hline Ocotea puberula & 1 & 0 & 2 & 0 & 0,6 & 0,0 \\
\hline Sloanea monosperma & 1 & 0 & 2 & 0 & 0,6 & 0,0 \\
\hline Syagrus romanzoffiana & 1 & 0 & 2 & 0 & 0,6 & 0,0 \\
\hline Tapirira guianensis & 1 & 0 & 2 & 0 & 0,6 & 0,0 \\
\hline Tibouchina granulosa & 1 & 0 & 2 & 0 & 0,6 & 0,0 \\
\hline Vitex polygama & 1 & 0 & 2 & 0 & 0,6 & 0,0 \\
\hline Zollernia ilicifolia & 1 & 0 & 2 & 0 & 0,6 & 0,0 \\
\hline Copaifera langsdorffii & 0 & 1 & 0 & 5 & 0,0 & 1,4 \\
\hline Cyathea delgadii & 0 & 1 & 0 & 5 & 0,0 & 1,4 \\
\hline Eugenia sphenophylla & 0 & 1 & 0 & 5 & 0,0 & 1,4 \\
\hline Pterocarpus rohrii & 0 & 1 & 0 & 5 & 0,0 & 1,4 \\
\hline Total & 155 & 72 & 310 & 360 & 100,0 & 100,0 \\
\hline
\end{tabular}


representadas por mais de um indivíduo, 15 ocorreram em apenas uma das áreas, 13 na área 1 e duas na área 2. Apenas $28 \%$ das espécies encontradas foram comuns a ambas as áreas.

As proporções de espécies de clímax, secundárias e pioneiras nas duas áreas também foram diferentes (figura 2). A área 1 conteve maior número de indivíduos de espécies climácicas e menor número de secundárias e pioneiras que a área 2. Em nenhuma das duas áreas, a porcentagem de indivíduos de espécies climácicas chegou a 50\%, para se considerar a área em estádio tardio de sucessão. Em ambas as amostras, a concentração maior de espécies pioneiras ocorreu nas regiões mais próximas à borda da Reserva. Comparação entre estudos no Planalto Paulistano A tabela 4 apresenta os valores das variáveis metodológicas e estruturais da vegetação de 16 levantamentos realizados no Planalto Paulistano. Foram encontradas três correlações significativas entre variáveis metodológicas e estruturais. O critério de inclusão (PAP) apresentou correlação negativa com a densidade absoluta total (DA) $\left(r_{S}=-0,95\right.$; $\mathrm{p}<0,0001)$. O melhor ajuste de curva foi obtido através do modelo de potência $\left(r^{2}=0,917\right.$, figura 3$)$.

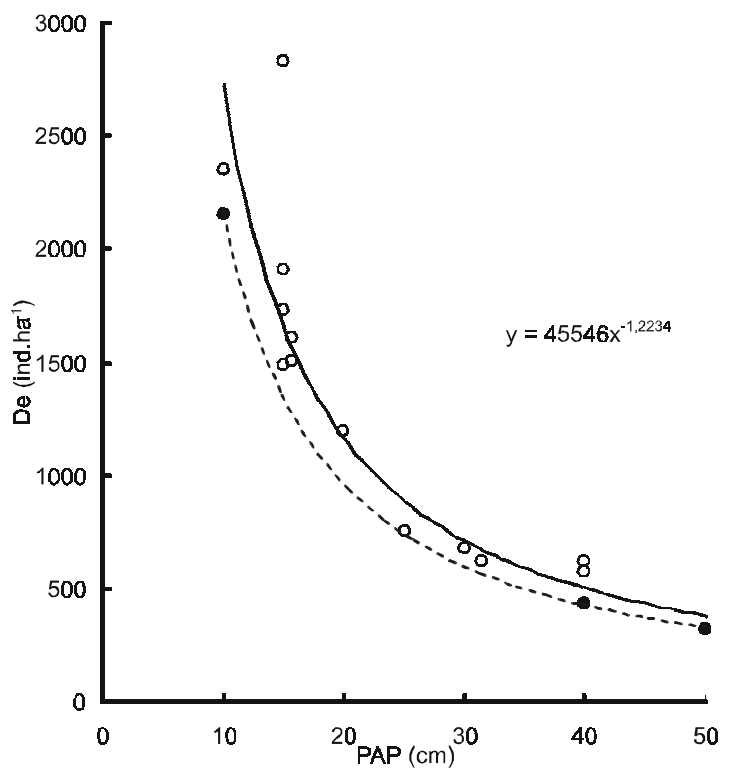

Figura 3. Relação entre critério de inclusão adotado e densidade absoluta total obtida em 16 levantamentos quantitativos da vegetação arbórea no Planalto Paulistano, SP. A linha sólida é o melhor ajuste de curva (descrita na equação) para o conjunto dos levantamentos. A linha tracejada une os pontos referentes a estudos na Reserva da Cidade Universitária "Armando de Salles Oliveira", São Paulo, SP.
O número de indivíduos amostrados $(\mathrm{N})$ apresentou correlação negativa com o número de espécies $(\mathrm{S})$ $\left(\mathrm{r}_{\mathrm{S}}=-0,80 ; \mathrm{p}=0,0002\right)$, com o melhor ajuste tendo sido obtido através do modelo de potência $\left(\mathrm{r}^{2}=0,653\right.$, figura 4). O número de indivíduos amostrados (N) apresentou correlação negativa com a porcentagem de espécies com um indivíduo $\left(\mathrm{S}_{1} / \mathrm{S}\right)\left(\mathrm{r}_{\mathrm{S}}=-0,83\right.$; $\mathrm{p}=0,0001)$. O melhor ajuste, neste caso, foi obtido através do modelo logarítmico $\left(\mathrm{r}^{2}=0,811\right.$, figura 5).

A área basal total (Do) e a densidade total (De) não apresentaram correlação com qualquer outra variável analisada. O número de espécies corrigido $\left(\mathrm{S}_{\text {corr }}\right)$ mostrou correlação significativa com $\mathrm{H}^{\prime}$ $\left(r_{\mathrm{S}}=0,75 ; \mathrm{p}=0,0012\right), \mathrm{J}^{\prime}\left(\mathrm{r}_{\mathrm{S}}=0,65 ; \mathrm{p}=0,0087\right)$ e com a porcentagem de espécies com um indivíduo corrigida $\left[\left(\mathrm{S}_{1} / \mathrm{S}\right)_{\text {corr }}\right]\left(\mathrm{r}_{\mathrm{S}}=0,67 ; \mathrm{p}=0,0042\right) . \mathrm{H}^{\prime}$ apresentou correlação significativa com $\mathrm{J}^{\prime}\left(\mathrm{r}_{\mathrm{S}}=0,79 ; \mathrm{p}=0,0005\right)$ e com $\left(\mathrm{S}_{1} / \mathrm{S}\right)_{\text {corr }}\left(\mathrm{r}_{\mathrm{S}}=0,66 ; \mathrm{p}=0,0069\right)$.

A mata da Reserva da CUASO apresenta, em comparação com as outras áreas de mata, valores relativamente baixos de quase todas as variáveis estruturais analisadas. Com relação àquelas que apresentam correlação com variáveis metodológicas, isto pode ser verificado nos gráficos das figuras 4,5

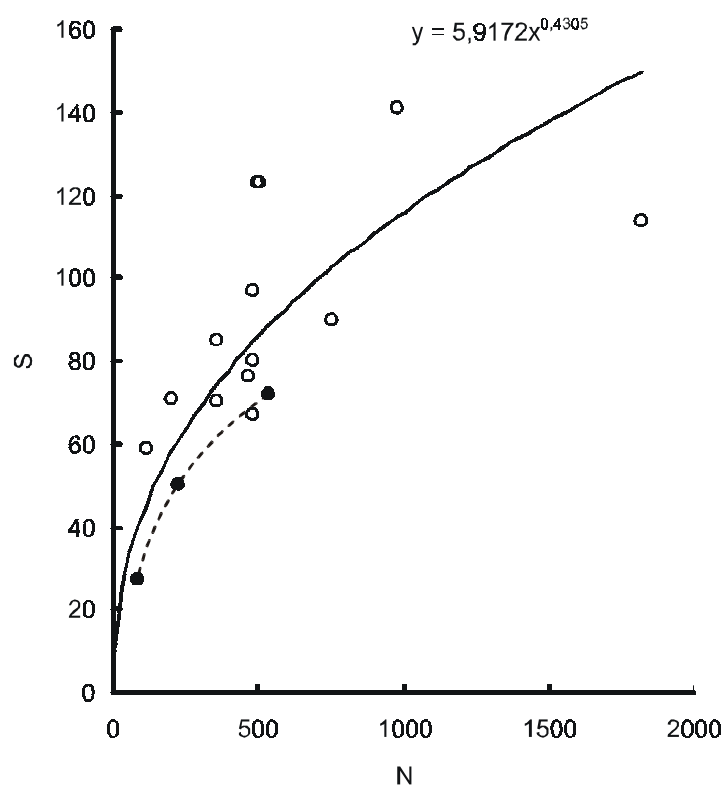

Figura 4. Relação entre o número de indivíduos amostrados e o número de espécies obtidas em 16 levantamentos quantitativos da vegetação arbórea no Planalto Paulistano, SP. A linha sólida é o melhor ajuste de curva (descrita na equação) para o conjunto dos levantamentos. A linha tracejada une os pontos referentes a estudos na Reserva da Cidade Universitária "Armando de Salles Oliveira", São Paulo, SP. 
Tabela 4. Dados sobre a estrutura de florestas no Planalto Paulistano, SP. Área: área total amostrada; PAP: perímetro do caule à altura do peito; $\mathrm{N}$ : número de indivíduos amostrados; $\mathrm{S}$ : número de espécies; $\mathrm{S}_{1} / \mathrm{S}$ : proporção de espécies representadas por apenas um indivíduo; H': índice de diversidade de Shannon e Wiener; J': índice de equabilidade de Pielou; De: densidade absoluta total; Do: dominância absoluta (área basal) total; - : dado não disponível.

P.M.: Parque Municipal; P.E.: Parque Estadual

\begin{tabular}{|c|c|c|c|c|c|c|c|c|c|}
\hline Referência & Local & $\begin{array}{l}\text { PAP } \\
(\mathrm{cm})\end{array}$ & $\mathrm{N}$ & $\mathrm{S}$ & $\mathrm{S}_{1} / \mathrm{S}(\%)$ & $\begin{array}{c}\mathrm{H}^{\prime} \\
\left.\text { (nats.ind }^{-1}\right)\end{array}$ & $\begin{array}{c}\mathrm{J} \\
(\%)\end{array}$ & $\begin{array}{c}\mathrm{De} \\
\text { (ind.ha }{ }^{-1} \text { ) } \\
\end{array}$ & $\begin{array}{c}\mathrm{H}^{\prime} \\
\left(\mathrm{m}^{2} \cdot \mathrm{ha}^{-1}\right)\end{array}$ \\
\hline Este trabalho & Reserva da CUASO & 50,0 & 227 & 50 & 42,0 & 3,04 & 77,79 & 324 & 20,1 \\
\hline Dislich (1996) & Reserva da CUASO & 40,0 & 86 & 27 & 55,6 & 2,57 & 77,98 & 430 & 23,9 \\
\hline Gorresio-Roizman (1993) & Reserva da CUASO & 10,0 & 539 & 72 & 27,8 & 3,67 & 85,81 & 2156 & 24,1 \\
\hline Aragaki \& Mantovani (1994) & $\begin{array}{l}\text { P. M. Alfredo Volpi, } \\
\text { São Paulo }\end{array}$ & 40,0 & 200 & 71 & 50,7 & 3,76 & 88,21 & 624 & 35,7 \\
\hline Aragaki (1997) & $\begin{array}{l}\text { P. M. Alfredo Volpi, } \\
\text { São Paulo }\end{array}$ & 40,0 & 114 & 59 & 62,7 & 3,78 & 92,70 & 570 & 28,8 \\
\hline Gomes (1992) & P.E. Fontes do Ipiranga & 25,0 & 756 & 90 & 30,0 & 3,44 & 76,45 & 756 & 16,8 \\
\hline *De Vuono (1985) A & P.E. Fontes do Ipiranga & 15,7 & 500 & 123 & 44,7 & 4,28 & 88,94 & 1604 & 20,0 \\
\hline * De Vuono (1985) B & P.E. Fontes do Ipiranga & 15,7 & 508 & 123 & 41,5 & 4,14 & 86,03 & 1506 & 33,5 \\
\hline Knobel (1995) & P.E. Fontes do Ipiranga & 20,0 & 357 & 70 & 44,0 & 3,28 & 77,09 & 1190 & 50,0 \\
\hline Nastri et al.. (1992) & P.E. Fontes do Ipiranga & 15,0 & 360 & 85 & 44,7 & 3,85 & 86,64 & 1488 & 26,0 \\
\hline *Tomasulo (1995) 1 & $\begin{array}{l}\text { P. M. Serra do Itapety, } \\
\text { Mogi das Cruzes }\end{array}$ & 15,0 & 480 & 97 & 35,0 & 3,80 & 83,10 & 1731 & 41,1 \\
\hline *Tomasulo (1995) 2 & $\begin{array}{l}\text { P. M. Serra do Itapety, } \\
\text { Mogi das Cruzes }\end{array}$ & 15,0 & 480 & 80 & 36,2 & 3,45 & 78,90 & 2829 & 36,2 \\
\hline *Tomasulo (1995) 3 & $\begin{array}{l}\text { P. M. Serra do Itapety, } \\
\text { Mogi das Cruzes }\end{array}$ & 15,0 & 480 & 67 & 29,8 & 3,30 & 78,70 & 1914 & 9,2 \\
\hline Gandolfi (1991) & Cumbica, Guarulhos & 30,0 & 1820 & 114 & 22,8 & 3,73 & 78,76 & 679 & 19,3 \\
\hline Tabarelli (1994) & P. E. Serra da Cantareira & 10,0 & 470 & 76 & 35,5 & - & - & 2350 & - \\
\hline Baitello et al. (1992) & P. E. Serra da Cantareira & 31,4 & 978 & 141 & 26,9 & 4,13 & 83,46 & 624 & 47,9 \\
\hline
\end{tabular}

* A, B e 1, 2, 3 referem-se as diferentes áreas estudadas pelos autores.

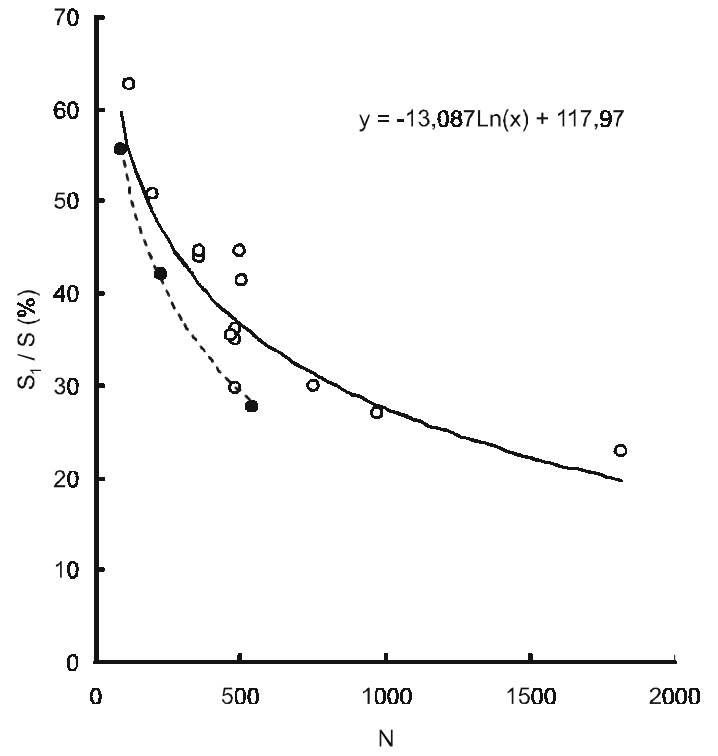

Figura 5. Relação entre número de indivíduos amostrados e porcentagem de espécies representadas por apenas um indivíduo $\left(\mathrm{S}_{1} / \mathrm{S}\right)$ em 16 levantamentos quantitativos da vegetação arbórea no Planalto Paulistano, SP. A linha sólida é o melhor ajuste de curva (descrita na equação) para o conjunto dos levantamentos. A linha tracejada une os pontos referentes a estudos na Reserva da Cidade Universitária "Armando de Salles Oliveira", São Paulo, SP. e 6, em que os pontos que representam estudos na Reserva da CUASO sempre apresentam valores baixos no eixo das ordenadas. Para as outras variáveis, os estudos na Reserva da CUASO têm, na quase totalidade dos casos, valores mais baixos que a mediana dos 16 estudos analisados (tabela 4).

Comparando-se as cinco espécies de maior área basal em 15 dos levantamentos realizados no Planalto Paulistano (tabela 5), percebem-se grandes diferenças. Não existe um único caso de espécie que seja a de maior área basal em dois levantamentos feitos em fragmentos diferentes. Espécies que aparecem em primeiro lugar em área basal são compartilhadas apenas entre levantamentos feitos no mesmo fragmento. Analisando-se as cinco espécies de maior área basal em cada levantamento, chega-se em 43 espécies. No cenário de maior diversidade possível, com nenhuma espécie compartilhada, seriam amostradas 75 espécies.

\section{Discussão}

A análise do componente arbóreo da floresta da Reserva da CUASO e sua comparação com outros trabalhos realizados no Planalto Paulistano 
Tabela 5. As cinco espécies com maiores dominâncias realtivas, listadas em ordem decrescente, em florestas no Planalto Paulistano, SP

\begin{tabular}{|c|c|c|c|c|c|}
\hline Referência & 1 & 2 & 3 & 4 & 5 \\
\hline Este trabalho & Alchornea sidifolia & Croton floribundus & $\begin{array}{l}\text { Machaerium } \\
\text { nyctitans }\end{array}$ & $\begin{array}{c}\text { Piptadenia } \\
\text { gonoacantha }\end{array}$ & Cedrela fissilis \\
\hline Dislich (1996) & Alchornea sidifolia & $\begin{array}{c}\text { Piptadenia } \\
\text { gonoacantha }\end{array}$ & Croton floribundus & Pterocarpus rohrii & $\begin{array}{l}\text { Cinnamomum } \\
\text { triplinerve }\end{array}$ \\
\hline $\begin{array}{l}\text { Gorresio-Roizman } \\
\text { (1993) }\end{array}$ & Alchornea sidifolia & Croton floribundus & $\begin{array}{l}\text { Machaerium } \\
\text { nyctitans }\end{array}$ & Cordia ecalyculata & $\begin{array}{l}\text { Machaerium } \\
\text { villosum }\end{array}$ \\
\hline $\begin{array}{l}\text { Aragaki \& Mantovani } \\
\text { (1994) }\end{array}$ & $\begin{array}{l}\text { Endlicheria } \\
\text { paniculata }\end{array}$ & Luehea grandiflora & $\begin{array}{c}\text { Machaerium } \\
\text { nyctitans }\end{array}$ & $\begin{array}{c}\text { Cupania } \\
\text { oblongifolia }\end{array}$ & Ocotea odorifera \\
\hline Aragaki (1997) & $\begin{array}{l}\text { Machaerium } \\
\text { nyctitans }\end{array}$ & Ocotea urbaniana & Luehea grandiflora & Ocotea diospyrifolia & $\begin{array}{l}\text { Aspidosperma } \\
\text { olivaceum }\end{array}$ \\
\hline Gomes (1992) & Ouratea semiserrata & Plinia glomerata & $\begin{array}{c}\text { Syagrus } \\
\text { romanzoffiana }\end{array}$ & $\begin{array}{c}\text { Coccoloba } \\
\text { crescentifolia }\end{array}$ & Maytenus robusta \\
\hline *De Vuono (1985) A & $\begin{array}{l}\text { Sclerolobium } \\
\text { denudatum }\end{array}$ & $\begin{array}{c}\text { Machaerium } \\
\text { villosum }\end{array}$ & $\begin{array}{l}\text { Syagrus } \\
\text { romanzoffiana }\end{array}$ & Alchornea sidifolia & Psychotria sessilis \\
\hline *De Vuono (1985) B & $\begin{array}{c}\text { Matayba } \\
\text { juglandifolia }\end{array}$ & Cabralea glaberrima & $\begin{array}{l}\text { Syagrus } \\
\text { romanzoffiana }\end{array}$ & $\begin{array}{c}\text { Cupania } \\
\text { oblongifolia }\end{array}$ & Ocotea kuhlmanii \\
\hline Knobel (1995) & $\begin{array}{c}\text { Matayba } \\
\text { juglandifolia }\end{array}$ & Cabralea glaberrima & $\begin{array}{l}\text { Syagrus } \\
\text { romanzoffiana }\end{array}$ & $\begin{array}{c}\text { Cupania } \\
\text { oblongifolia }\end{array}$ & Ocotea kuhlmanii \\
\hline Nastri et al. (1992) & Luehea grandiflora & $\begin{array}{c}\text { Copaifera } \\
\text { langsdorfii }\end{array}$ & $\begin{array}{l}\text { Syagrus } \\
\text { romanzoffiana }\end{array}$ & Persea pyrifolia & Alchornea sidifolia \\
\hline Gandolfi (1991) & Ocotea corymbosa & Tapirira guianensis & Sapium glandulatum & Sebastiania serrata & Protium widgrenii \\
\hline Tabarelli (1994) & $\begin{array}{c}\text { Cupania } \\
\text { oblongifolia }\end{array}$ & $\begin{array}{l}\text { Alchornea } \\
\text { triplinervia }\end{array}$ & Heisteria silvianii & Cabralea canjerana & Matayba guianensis \\
\hline *Tomasulo (1995) 1 & Guapira opposita & Miconia cabucu & $\begin{array}{c}\text { Sloanea } \\
\text { monosperma }\end{array}$ & Clethra scabra & Hirtella hebeclada \\
\hline *Tomasulo (1995) 2 & Guapira opposita & $\begin{array}{l}\text { Aspidosperma } \\
\text { olivaceum }\end{array}$ & Miconia саьиси & Casearia obliqua & Maytenus robusta \\
\hline *Tomasulo (1995) 3 & Guapira opposita & $\begin{array}{l}\text { Aspidosperma } \\
\text { olivaceum }\end{array}$ & Tapirira guianensis & Pera glabrata & Miconia саbиси \\
\hline
\end{tabular}

*A, B e 1, 2, 3 referem-se as diferentes áreas estudadas pelos autores.

evidenciam a diversidade apresentada nos fragmentos florestais da região, sob diversos aspectos e em diversas escalas espaciais. As florestas ombrófilas densas apresentam heterogeneidade intrínseca excepcionalmente elevada, devido a fatores históricos, à sua dinâmica natural, às características físicas locais e ao próprio processo de fragmentação (Mantovani 2001).

Além da variação na diversidade de espécies (H') em cada área estudada, pode-se reconhecer, no interior da mata da CUASO, a existência de concentrações de indivíduos de estádios sucessionais diferentes, nas duas áreas analisadas e a substituição total de uma das três espécies mais abundantes, além de alterações em variáveis comumente utilizadas na descrição de florestas, como número de espécies, proporção de espécies representadas por um indivíduo, diversidade $\left(\mathrm{H}^{\prime}\right)$, equabilidade (J'), densidade absoluta total e dominância absoluta total, entre áreas separadas por distâncias de alguns quilômetros a dezenas de quilômetros.

As variações encontradas no interior da Reserva da CUASO, afora a heterogeneidade intrínseca deste tipo florestal, devem-se à existência de um "mosaico de áreas em diversos estádios de degradação e regeneração" percebido subjetivamente por Rossi (1994). Esse mosaico é causado tanto pela dinâmica natural da floresta, com a queda de grandes árvores e conseqüente abertura de clareiras e posterior regeneração, quanto pela perturbação antrópica sofrida pela vegetação no passado e à fragmentação.

As variáveis ligadas à diversidade de espécies (H', J', número de espécies) aparecem correlacionadas entre si. A correlação entre número de espécies e H' e entre J' e H' é esperada, uma vez que a riqueza, medida pelo número de espécies, e a equabilidade, medida através de J', são os componentes da diversidade de espécies, medida através de H'. No entanto, a riqueza e a equabilidade $\mathrm{J}$ ' também aparecem correlacionadas, o que não era previsto. É possível que esta correlação seja um artefato, devido ao modo como é calculado o índice J', tornando-o não independente da riqueza (Smith \& Wilson 1996). Neste caso, a própria utilização deste índice de eqüabilidade deveria idealmente ser abandonada em favor de outro índice independente da riqueza de 
espécies, como alguns dos que foram analisados por estes autores. No entanto, os autores detectaram uma influência importante do número de espécies sobre J' para valores de número de espécies abaixo de 25 , sendo que nos estudos aqui analisados este número sempre foi maior.

A correlação entre o número de espécies, $\mathrm{H}^{\prime} \mathrm{e}$ J' faz com que qualquer um dos três valores possa ser utilizado para se avaliar a diversidade, em uma comparação entre florestas, desde que se considere o número de indivíduos amostrados como capaz de alterar o número de espécies. A porcentagem de espécies com um indivíduo $\mathrm{S}_{1} / \mathrm{S}$ também faz parte deste "complexo de diversidade", estando correlacionada a duas das três variáveis ligadas diretamente à diversidade, e também poderia teoricamente ser usada como medida da diversidade. Isto, porém, não seria muito prático: para se obter este valor é necessária a obtenção dos mesmos dados de campo que para as três outras variáveis, ou seja, a identificação de determinado número de indivíduos. Em outras palavras, o cálculo de $S_{1} / S$ não traz mais informações que os outros índices, podendo ser deixado de lado, sem prejuízo de informação sobre a floresta a ser descrita.

Por outro lado, as variáveis ligadas à estrutura da floresta, como a densidade e a dominância total, não estão correlacionadas entre si ou com a diversidade de espécies (H', J', $\mathrm{S}$ ou $\left.\mathrm{S}_{1} / \mathrm{S}\right)$. De certa forma, seria esperado que houvesse correlação entre a diversidade e a área basal, uma vez que ambos tendem a aumentar ao longo do processo de sucessão ecológica. Este resultado pode significar que a variação encontrada entre as florestas analisadas não pode ser reduzida ao tempo de sucessão.

Já a variação de densidade ao longo da sucessão deve depender do critério de inclusão adotado: a densidade de árvores de maior porte deve ser aumentada, enquanto a das de menor porte deve diminuir, como resposta à diminuição da irradiância no subosque com o aumento do porte da floresta. Ocorreria, assim, uma mudança no formato da distribuição de freqüências de diâmetro ao longo da sucessão, mascarando eventuais relações entre tempo de sucessão e densidade, ao incluirem-se trabalhos com critérios de inclusão muito variados no estudo. Uma análise mais profunda deste aspecto seria possível se os dados brutos de todos os estudos estivessem disponíveis. Por outro lado, em florestas mais maduras, abaixo do dossel, poderão estabelecer- se muitas espécies de árvores típicas deste ambiente e jovens de árvores dominantes, representadas por densidades elevadas.

Fragmentos florestais pequenos e isolados, originados por desmatamentos em uma paisagem originalmente coberta por floresta, apresentam uma tendência ao empobrecimento, devido à incapacidade de regeneração de muitas populações nessas condições (Turner et al. 1996). A Reserva da CUASO não apenas é isolada hoje, como também o foi, em um grau provavelmente crescente ao longo do tempo, durante todo o processo de sucessão ecológica que deu origem à sua cobertura florestal atual. Os baixos valores de diversidade obtidos na mata da CUASO provavelmente estão relacionados a isto, já que o critério de inclusão aqui empregado é o mais restritivo e, portanto, inclui na amostra apenas árvores de dossel e emergentes, que formam o componente arbóreo de florestas tropicais mais diverso. Nem todas as espécies têm a mesma capacidade de dispersar suas sementes até um fragmento isolado, o que por si só já deveria diminuir a diversidade final de espécies, mesmo se pequenas porções isoladas de floresta pudessem manter diversidade equivalente à da floresta contínua.

As características intrínsecas da floresta ombrófila densa, o histórico de inserção na paisagem local e sua interação com o processo sucessional, têm grande influência na determinação das diferenças encontradas entre os trechos de florestas estudados no Planalto Paulistano. Infelizmente, porém, estes aspectos não são muito fáceis de serem descritos para cada fragmento atual. Características topográficas e geomorfológicas, condições de mesoclima associadas, tamanho e forma dos fragmentos, características de solo e regime de perturbação - por poluição, por exemplo - também devem ter importância, assim como as interações entre os diversos fatores apontados.

Agradecimentos - Ricardo Dislich foi financiado pela CAPES (bolsa de mestrado) durante a realização do trabalho de campo.

\section{Referências bibliográficas}

AB' SÁBER, A.N. 1963. Originalidade do sítio da cidade de São Paulo. Acrópole 295/296:239-246.

AB' SÁBER, A.N. 1970. O mosaico primário de matas e cerrados do Planalto Paulistano. Cadernos de Ciências da Terra 6:24-26. 
ARAGAKI, S. 1997. Florística e estrutura de trecho remanescente de floresta no planalto paulistano (SP). Dissertação de mestrado, Universidade de São Paulo, São Paulo.

ARAGAKI, S. \& MANTOVANI, W. 1994. Estudos estruturais e taxonômicos de trecho remanescente de floresta no Parque Municipal Alfredo Volpi (São Paulo, SP). In Anais do III Simpósio de Ecossistemas da Costa Brasileira (S. Watanabe, coord.). Academia de Ciências do Estado de São Paulo. v.2, p.68-80.

ARAGAKI, S. \& MANTOVANI, W. 1998. Caracterização do clima e da vegetação de remanescente florestal no Planalto Paulistano (SP). In Anais do IV Simpósio de Ecossistemas Brasileiros (S. Watanabe, coord.). Academia de Ciências do Estado de São Paulo. v.2, p.25-36.

BAITELLO, J.B. \& AGUIAR, O.T. 1982. Flora fanerogâmica da Serra da Cantareira (São Paulo). Silvicultura em São Paulo 16A:582-590.

BAITELLO, J.B., AGUIAR, O.T., ROCHA, F.T., PASTORE, J.A. \& ESTEVES, R. 1992. Florística e fitossociologia do estrato arbóreo de um trecho da Serra da Cantareira (Núcleo Pinheirinho) - SP. Revista do Instituto Florestal 4:291-297.

BUDOWSKI, G. 1970. The distinction between old secondary and climax species in tropical central american lowland rainforests. Tropical Ecology 11:44-48.

CRONQUIST, A. 1981 An integrated system of classification of flowering plants. Columbia University Press, New York.

DE VUONO, Y.S. 1985. Fitossociologia do estrato arbóreo da floresta da Reserva do Instituto de Botânica (São Paulo - SP). Tese de doutorado, Universidade de São Paulo, São Paulo.

DISLICH, R. 1996. Florística e estrutura do componente epifítico vascular na mata da Reserva da Cidade Universitária "Armando de Salles Oliveira", São Paulo, SP. Dissertação de mestrado, Universidade de São Paulo, São Paulo.

GANDOLFI, S. 1991. Estudo florístico e fitossociológico de uma floresta residual na área do Aeroporto Internacional de São Paulo, Município de Guarulhos - SP. Dissertação de Mestrado, Universidade Estadual de Campinas, Campinas.

GANDOLFI, S., LEITÃO-FILHO, H.F. \& BEZERRA, C.L.F. 1995. Levantamento florístico e caráter sucessional das espécies arbustivo-arbóreas de uma floresta mesófila semidecídua no município de Guarulhos, SP. Revista Brasileira de Biologia 55:735-767.

GARCIA, R.J.F. 1995. Composição florística dos estratos arbóreo e arbustivo da mata do Parque Santo Dias (São Paulo - SP, Brasil). Dissertação de mestrado, Universidade de São Paulo, São Paulo.

GOMES, E.P.C. 1992. Fitossociologia do componente arbóreo de um trecho de mata em São Paulo, SP. Dissertação de mestrado, Universidade de São Paulo, São Paulo.

GORRESIO-ROIZMAN, L. 1993. Fitossociologia e dinâmica do banco de sementes de populações arbóreas de floresta secundária em São Paulo, SP. Disertação de mestrado, Universidade de São Paulo, São Paulo.

JOLY, A.B. 1950. Estudo fitogeográfico dos campos do Butantã. Boletim da Faculdade de Filosofia Ciências e Letras, Universidade de São Paulo, Botânica 8:5-68.

KNOBEL, M.G. 1995. Aspectos da regeneração natural do componente arbóreo-arbustivo de trecho da floresta da Reserva Biológica do Instituto de Botânica em São Paulo, SP. Dissertação de mestrado, Universidade de São Paulo, São Paulo.
MAGURRAN, A.E. 1988. Ecological diversity and its measurement. Princeton University Press, Princeton.

MANTOVANI, W. 2001. A paisagem dinâmica. In Intervales (C. Leonel, ed.). Fundação Florestal, São Paulo, p.81-91.

MELHEM, T.S., GIULIETTI, A.M.; FORERO, E., BARROSO, G.M., SILVESTRE, M.S.F., JUNG, S.L., MAKINO, H., MELO, M.M.R.F., CHIEA, S.C., WANDERLEY, M.G.L., KIRIZAWA, M. \& MUNIZ, C. 1981. Planejamento para elaboração da "Flora Fanerogâmica da Reserva do Parque Estadual das Fontes do Ipiranga (São Paulo - Brasil)". Hoehnea 9:63-74.

MUELLER-DOMBOIS, D. \& ELLENBERG, H. 1974. Aims and methods of vegetation ecology. John Wiley, New York.

NASTRI, V.D.F., CATHARINO, E.L.M., ROSSI, L., BARBOSA, L.M., PIRRÉ, E., BEDINELLI, C., ASPERTI, L.M., DORTA, R.O. \& COSTA, M.P. 1992. Estudos fitossociológicos em uma área do Instituto de Botânica de São Paulo utilizados em programas de educação ambiental. Revista do Instituto Florestal 4:219225.

PASTORE, J.A., AGUIAR, O.T., ESTEVES, R. \& SILVA, C.A.F. 1992. Flora arbóreo-arbustiva do Parque Chico Mendes, município de São Bernardo do Campo (SP). Revista do Instituto Florestal 4:269-273.

PETRONE, P. 1995. Aldeamentos paulistas. Editora da Universidade de São Paulo, São Paulo.

PIELOU, E.C. 1975. Ecological diversity. WilleyInterscience, New York.

ROSSI, L. 1994. A flora arbóreo-arbustiva da mata da Reserva da Cidade Universitária "Armando de Salles Oliveira" (São Paulo, Brasil). Boletim do Instituto de Botânica 9:1-105.

SMITH, B. \& WILSON, J.B. 1996. A consumer's guide to evenness indices. Oikos 76:70-82.

TABARELLI, M. 1994. Clareiras naturais e a dinâmica sucessional de um trecho de floresta na Serra da Cantareira, SP. Dissertação de mestrado, Universidade de São Paulo, São Paulo.

TABARELLI, M. \& MANTOVANI, W. 1997. Colonização de clareiras naturais na floresta atlântica no Sudeste do Brasil. Revista Brasileira de Botânica 20:57-66.

TOMASULO, P.L.B. 1995. Análise da composição florística e estrutura da vegetação como subsídio ao plano de manejo para o Parque Municipal da Serra do Itapety, Mogi das Cruzes, SP. Dissertação de mestrado, Universidade Federal de Minas Gerais, Belo Horizonte.

TORRES, R.B., MARTINS, F.R. \& KINOSHITA, L.S. 1997. Climate, soil and tree flora relationships in forests in the state of São Paulo, southeastern Brazil. Revista Brasileira de Botânica 20:41-49.

TURNER, I.M., CHUA, K.S., ONG, J., SOONG, B. \& TAN, H. 1996. A century of plant species loss from an isolated fragment of lowland tropical rain forest. Conservation Biology 10:1229-1244.

USTERI, A. 1911. Flora der Umgebung der Stadt São Paulo in Brasilien. Gustav Fischer, Jena.

VELOSO, H.P., RANGEL FILHO, A.L.R. \& LIMA, J.C.A. 1991. Classificação da vegetação brasileira, adaptada a um sistema universal. Fundação Instituto Brasileiro de Geografia e Estatística, Rio de Janeiro.

ZAR, J.H. 1999. Biostatistical analysis. 4 ed. Prentice Hall, Upper Saddle River. 